University of South Carolina

Scholar Commons

Faculty Publications

Economics Department

2-1993

\title{
Aggregate Vote Functions for the US. Presidency, Senate, and House
}

Henry W. Chappell

University of South Carolina - Columbia, chappell@moore.sc.edu

Motoshi Suzuki

Follow this and additional works at: https://scholarcommons.sc.edu/econ_facpub

Part of the Business Commons, and the Political Science Commons

\section{Publication Info}

Published in Journal of Politics, Volume 55, Issue 1, 1993, pages 207-217.

http://journals.cambridge.org/action/displayJournal?jid=JOP

(C) 1993 by Cambridge University Press

This Article is brought to you by the Economics Department at Scholar Commons. It has been accepted for inclusion in Faculty Publications by an authorized administrator of Scholar Commons. For more information, please contact digres@mailbox.sc.edu. 


\title{
Aggregate Vote Functions for the U.S. Presidency, Senate, and House
}

\author{
Henry W. Chappell, Jr. \\ University of South Carolina \\ Motoshi Suzuki \\ University of North Texas
}

In this paper, we estimate vote functions for presidential, House, and Senate elections in the United States using a seemingly unrelated regressions technique adapted to the case of unequal numbers of observations across equations. Our method facilitates rigorous comparisons of voting behavior across election types and provides efficiency gains over ordinary least squares.

Our analysis focuses on comparisons across vote functions. We find that: (1) economic variables appear to influence outcomes in all election types, but they are more important in presidential elections than in House or Senate elections; (2) the hypothesis that voters attach equal relative weights to inflation and growth across election types cannot be rejected; (3) incumbency power affects both Senate and House elections but is more important in the House; (4) mid-term effects in House and Senate elections represent a penalty for the party controlling the presidency.

$\mathbf{T}_{\mathrm{he}}$

he political science literature does not lack for studies linking aggregate voting outcomes with macroeconomic conditions. In a pioneering study, Kramer (1971) analyzed the effects of economic conditions on aggregate vote shares in congressional and presidential elections in the United States. He found that per capita income growth led to significant gains for the party of the incumbent president. Other studies have followed, with most supporting the hypothesis that elections are influenced by economic events. ${ }^{1}$ Despite the emerging consensus that "economics matters," two recent studies provide a contrasting view for congressional elections. Erikson (1990) finds that an economic growth variable adds no explanatory power to a properly specified model for U.S. House elections, and Alesina and Rosenthal (1989) present similar findings for both the House and the Senate.

Our purpose in this paper is to pursue issues posed by the recent contributions of Erikson and Alesina-Rosenthal while introducing a methodological refinement for the estimation of vote functions. An important premise of our paper is that

We thank Robert Erikson for providing us with 1988 data for the net candidate evaluation. We also acknowledge the helpful comments of John Londregan and two anonymous referees.

'For example, vote functions for presidential or congressional elections in the United States have been estimated by Stigler (1973), Arcelus and Meltzer (1975), Lepper (1974), Tufte (1975, 1978), Fair (1988), and Erikson (1989).

THE JOURNAL OF POLITICS, Vol. 55, No. 1, February 1993, Pp. 207-217

(C) 1993 by the University of Texas Press 
vote functions for House, Senate, and presidential elections are likely to be related; i.e., they may indicate similar voter responses to economic conditions or random shocks. This has two important consequences. First, efficiency in estimation implies that vote functions should be treated as "systems" of equations jointly explaining vote totals for the various election types. Second, hypothesized behavioral regularities across elections can be modeled as testable cross-equation restrictions. Each of these points could be important in analyzing the questions raised by Erikson and Alesina-Rosenthal. Detecting the statistical significance of income growth in a congressional vote function that relies on few observations could easily hinge on the efficiency of the estimation technique. Moreover, formal comparisons of the impacts of income growth across presidential and congressional vote functions will require tests of cross-equation restrictions.

The issues we focus on have not been overlooked in earlier works, but they have not always been handled in the most appropriate fashion. Most studies have estimated vote functions for the House, Senate, or presidency in isolation. As a consequence, comparisons across vote functions have usually been informal. Kramer's pathbreaking study was an early exception that analyzed both presidential and congressional elections. Unfortunately Kramer required key parameters to be equal across equations and failed to test the restrictions he imposed.

Following Kramer, Lepper (1974) estimated a seemingly unrelated regressions (SUR) model to explain jointly congressional and presidential votes. Her analysis implied that the cross-equation restrictions imposed by Kramer could be rejected. However Lepper's study also suffers from what could be a severe limitation. To apply the standard SUR estimator (as implemented in most statistical software packages), sample periods for the equations in the model must be identical. Lepper therefore dropped all mid-term elections from the congressional vote function sample. Given the small number of election observations available, this represents a drastic and probably unnecessary loss of information. Calvert and Ferejohn (1984) similarly excluded mid-term election observations when they applied SUR methods to study presidential coattails in congressional vote functions.

Of course, on-year and mid-term congressional elections may be intrinsically different from one another, as Erikson (1990) has argued. This suggests that pooling data from on-year and mid-term elections is inappropriate and, conversely, that dropping off-year elections as Lepper, and Calvert and Ferejohn did is appropriate. Ultimately, this issue must be resolved empirically. The hypothesis that parameters of on-year and mid-term congressional elections differ is testable, and decisions about pooling or not pooling data from on-year and mid-term elections can then be informed by the outcome of such a test.

In this paper, we estimate vote functions for presidential, House, and Senate elections using a seemingly unrelated regressions technique adapted to the case of unequal numbers of observations across equations. This technique provides efficiency gains associated with a systems estimator and also permits us to make use of all available observations for the House and Senate election series. Statistical tests of a variety of cross-equation restrictions will permit us to formally compare voting 
behavior across election types. Our method enables us to investigate substantive questions about political behavior that have received little prior attention, and it also provides more powerful tests of hypotheses that have been considered before.

\section{THE EMPIRICAL MODEL}

The specification of our empirical model is essentially orthodox in its treatment of vote functions. It consists of these three equations:

$$
\begin{aligned}
& P V_{t}=\alpha_{0}+\alpha_{1} \dot{Y}_{t}+\alpha_{2} \dot{P}_{t}+\alpha_{3} C_{t}+\alpha_{4} D P E R_{t}+e_{P t} \\
& S V_{t}=\beta_{0}+\beta_{1} \dot{Y}_{t}+\beta_{2} \dot{P}_{t}+\beta_{3} C_{t}+\beta_{4} S I N C_{t}+\beta_{5} M T_{t}+e_{\mathrm{St}} \\
& H V_{t}=\gamma_{0}+\gamma_{1} \dot{Y}_{t}+\gamma_{2} \dot{P}_{t}+\gamma_{3} C_{t}+\gamma_{4} \mathrm{HINC}_{t}+\gamma_{5} M T_{t}+e_{H t}
\end{aligned}
$$

where:

$P V_{t}=$ The incumbent party's percentage of the two-party vote in the presidential election occurring in year $t$ (if such an election takes place).

$S V_{t}=$ The percentage of the nationwide two-party vote in Senate elections that favors the party of the incumbent president in year $t$.

$H V_{t}=$ The percentage of the nationwide two-party vote in House elections that favors the party of the incumbent president in year $t$.

$\dot{Y}_{t}=$ The percentage growth rate of real per capita GNP in year $t$.

$\dot{P}_{t}^{t}=$ The percentage growth rate of the GNP deflator in year $t$.

$C_{t}=$ The (net) candidate advantage of the incumbent party's presidential candidate. This measure is based on answers to an open-ended poll question asking respondents to list things they like or dislike about each candidate. $C_{t}$ is defined as the mean of in-party "likes" and out-party candidate "dislikes" minus the out-party candidate "likes" and in-party candidate "dislikes" for National Election Survey (NES) respondents in year $t$. Issue-based and group-based likes and dislikes are excluded. This variable is set equal to zero in mid-term congressional elections.

$D P E R_{t}=$ A dummy variable equal to one if an incumbent president is running for reelection in year $t$, otherwise equal to zero. ${ }^{2}$

$H I N C_{t}=$ The percentage of House members belonging to the incumbent president's party in year $t$.

$S I N C_{t}=$ The percentage of Senate members whose seats are being contested in the year $t$ election who belong to the incumbent president's party.

$M T_{t}=$ A dummy variable equal to one if the year $t$ elections are mid-term elections; otherwise equal to zero.

$e_{P t}, e_{g t}$, and $e_{H t}$ are random error terms drawn from a multivariate normal distribution.

$\alpha_{i}, \beta_{i}$, and $\gamma_{i}$, are parameters.

${ }^{2}$ Following Fair, we define Ford as a nonincumbent. 
The specification of the voting model is conventional in including per capita economic growth and inflation as explanatory variables (although both Erikson [1989] and Alesina-Rosenthal [1989] exclude inflation). Following Erikson (1989) and Tufte (1978), the "candidate evaluation," $C$, is included in the presidential vote function to capture the effects of candidate-specific attributes that are not related to issue stances. ${ }^{3} \mathrm{By}$ also including $C$ in the House and Senate vote functions we capture the effects of presidential coattails specifically related to the "likability" of presidential candidates. If high values for $C$ aid both the winning president and his party's nominees in Senate and House races in on-year elections, and if such effects are absent in the off-year elections, then coattails-related mid-term losses for the president's party will be observed.

Similar effects can result if the error for the presidential vote equation is positively correlated with errors for the congressional equations. When the error term favors the Republican candidate in a presidential election, the Republican is most likely to win. If cross-equation error correlations are positive, Republicans are also likely to do well in congressional elections. However, when the next mid-term election arrives, the errors will on average be less favorable for the Republicans (i.e., they revert to the mean), and mid-term losses for Republicans will typically be observed.

Following Alesina-Rosenthal (1989), the House and Senate equations also include $M T$, a dummy variable indicating mid-term elections. According to the Alesina-Rosenthal hypothesis, the electorate votes against the party of the incumbent president in mid-term congressional elections to "moderate" the president's partisan extremism. If economic variables follow a partisan electoral cycle, moderating voting at mid-term can induce a spurious correlation between economic performance and congressional election outcomes unless the mid-term effect is controlled for. A negative coefficient for $M T$ indicates a mid-term "penalty for the party controlling the presidency." Although the coattail effects described earlier can explain mid-term losses for the party of the current president, they cannot explain why the vote share of incumbent presidents would be smaller in mid-term than on-year elections. The latter effect, if it exists, can be captured by $M T$. Both Erikson (1988) and Alesina-Rosenthal have reported large $M T$ effects. ${ }^{4}$

$D P E R, H I N C$, and $S I N C$ control for advantages of incumbency in the three equations. Following Fair (1988), we use DPER in the presidential vote equation to indicate an incumbent running for reelection. In the House equation, HINC measures the fraction of incumbent House members belonging to the president's party. Incumbent advantages should result in a positive coefficient for this variable. ${ }^{5}$

${ }^{3}$ As Fair (1988) notes, it is not appropriate to suppose that the candidate evaluation "causes" or "explains" voting decisions-we do not know what ultimately causes candidate likes and dislikes. However, it can serve as a proxy for unobserved candidate attributes for which the model should control, and it is appropriate to include it in the model for this reason.

${ }^{4}$ Erikson (1988) provides a detailed analysis of mid-term effects in congressional elections.

${ }^{5}$ We chose not to measure incumbent strength by the partisan breakdown of incumbents and challengers in the current election. Endogeneity of incumbent choices to run or retire would make simultaneity an issue for such measures. 
SINC is a similar measure for the Senate, but it is measured only over those Senate seats being contested in the current election. Admittedly the incumbency variables will capture some effects of long-run political trends as well as short-run incumbent advantages. Regardless of the ultimate source of these "incumbency" effects, it is desirable to control for them so that consistent estimates of remaining parameters can be obtained. ${ }^{6}$

Our model assumes that differences between mid-term and on-year congressional elections are adequately captured by the inclusion of a mid-term dummy. This is a testable restriction. As a preliminary to our analysis, we therefore estimated a more general model which permitted coefficients for the incumbency and economic variables to vary across mid-term and on-year elections. Based on this estimation, we were not able to reject the hypothesis that these coefficients were equal across mid-term and on-year elections in both House and Senate equations.? We conclude that pooling is empirically justifiable so long as the mid-term dummy is included in House and Senate vote functions.

Systems of equations with correlated errors are typically treated as seemingly unrelated regressions, ${ }^{8}$ as in Lepper (1974) and Calvert and Ferejohn (1984). As we have noted, estimation of the SUR model is complicated here by the presence of differing sample periods for congressional and presidential elections; in midterm years we do not observe the presidential vote variable. To handle this complication we employ a generalized least squares $(G L S)$ estimator proposed by Schmidt (1977). ${ }^{9}$ In a Monte Carlo study of the $S U R$ technique for equations with

"As an alternative incumbency power variable for the Senate equation, we adjusted $S I N C$ to account for differences in state populations. The alternate variable was measured as the total population of states in which a currently contested Senate seat was held by a member of the party of the president, divided by the population of all states in which a Senate seat was contested. Using the adjusted variable slightly worsened the overall fit of the model and lessened the significance of income growth in the Senate vote function, but estimates were otherwise similar. We have also estimated models in which the incumbent party's lagged vote share replaces the incumbency variables in House and Senate equations. Again results were similar, but the overall fit of the model was worsened.

'For the House equation estimated by OLS, a joint test of equal coefficients in on-year and midterm elections for the variables $\dot{Y}, \dot{P}$, and $H I N C$ produced an $F$-statistic of 0.63 , which is less than 3.49 , the critical value for $F_{05}(3,12)$. The hypothesis is not rejected. For the Senate, the $F$-statistic was 0.59 , and again the hypothesis is not rejected. Tests of equality for individual coefficients were also not rejected.

${ }^{8}$ Zellner (1962) provides an early description of estimation methods for the seemingly unrelated regressions model.

'Equations were initially estimated by ordinary least squares (OLS), and OLS residuals were used to construct a covariance matrix for the equations' error terms. Following Hocking and Smith (1968), we employ all observations in computing relevant covariances. Then, given the estimated covariance matrix, remaining model parameters were estimated by generalized least squares. In effect these estimates are "conditional" maximum likelihood estimates (conditional upon the estimated error covariance matrix). They have the same asymptotic distributions as full information maximum-likelihood estimates and tests based upon the likelihood function are appropriate (Schmidt 1977). An appendix presenting the likelihood function for the model and a TSP program used in estimation is available from the authors upon request. Similar techniques have been used in the context of voting and popularity functions by Chappell (1990) but have not previously been employed to estimate systems of vote equations. 
unequal numbers of observations, Schmidt showed that coefficient standard errors can be as much as $25 \%$ lower than those obtained via OLS in small samples. Such gains could be critical in this study, given the paucity of election observations.

\section{Empirical Results}

We have estimated our model using data from 21 congressional elections and 11 presidential elections over the 1948-1988 period in the United States. ${ }^{10}$ Estimates are reported in table 1; ancillary statistical tests are provided in table 2 . Although our discussion focuses on the results of the SUR model estimation, OLS estimates are provided for purposes of comparison.

Two sets of $t$-statistics accompany the SUR estimates in table 1 . The first set consists of asymptotic $t$-values, estimated by the method of White (1982). The use of White's method ensures that $t$-statistics are robust to a variety of possible specification errors. Unfortunately $t$-statistics based on an asymptotic distribution are of questionable value when sample sizes are quite small. We therefore present a set of small-sample $t$-statistics estimated by means of a parametric bootstrapping technique suggested by Efron $(1982,30) .{ }^{11}$ The table reveals that the two sets of $t$ statistics are quite similar, although there is some tendency for the asymptotic $t$ values to be inflated compared to those produced by bootstrapping. Despite that tendency, the inferences we draw are robust across the two sets of $t$-statistics.

We will in turn discuss the impacts of economic performance on elections, the implications of our results about mid-term congressional election effects, and the impacts of incumbency variables. We will also discuss tests of cross-equation restrictions and the benefits of the $S U R$ estimation procedure. In addition to estimating the model presented above, we have undertaken a variety of sensitivity tests. All qualitative findings appear to be robust to the changes in specification we have considered. Details of sensitivity testing are not reported here, but are described at greater length in a working paper available from the authors.

Economic Performance. Consistent with the findings of Erikson (1989), per capita GNP growth in the year of the election has dramatic impacts on presidential election outcomes. Our results show that a one percentage point increase in economic growth provides the incumbent party with approximately 1.4 percentage points of additional vote share. This effect is smaller than that reported by

${ }^{10} \mathrm{~A}$ complete listing of data used in this analysis is available from the authors upon request.

${ }^{1}$ This method involves these steps: (1) estimate the model by the method described in footnote 9 ; (2) construct residuals for each equation and use these to estimate the variance-covariance matrix of the multivariate normal distribution which generates the error terms; (3) use a random number generator to draw a sample of errors from that multivariate normal distribution; (4) construct new values for each dependent variable by adding the appropriate randomly drawn error to the predicted value obtained from the original estimation; (5) use the newly constructed data to estimate the model by the method described in footnote $9 ;(6)$ repeat steps (3)-(5) 100 times, producing 100 sets of estimates; (7) compute a standard deviation for each coefficient using the sample of 100 estimates - this is the estimated standard error. 


\section{TABLE 1}

VOTE FunCtION EsTIMATES FOR THE UNITED STATES: 1948-1988

\begin{tabular}{|c|c|c|c|c|c|c|}
\hline \multirow[b]{2}{*}{ Variable } & \multicolumn{3}{|c|}{ SUR Model Estimates } & \multicolumn{3}{|c|}{ OLS Estimates } \\
\hline & President & Senate & House & President & Senate & House \\
\hline Constant & $\begin{array}{c}49.21 \\
(37.78) \\
{[28.26]}\end{array}$ & $\begin{array}{c}39.59 \\
(22.74) \\
{[17.47]}\end{array}$ & $\begin{array}{c}35.92 \\
(21.38) \\
{[22.91]}\end{array}$ & $\begin{array}{l}49.76 \\
(21.74)\end{array}$ & $\begin{array}{l}40.32 \\
(12.52)\end{array}$ & $\begin{array}{c}34.04 \\
(13.54)\end{array}$ \\
\hline$\dot{Y}$ (Growth) & $\begin{array}{c}1.38 \\
(6.55) \\
{[3.92]}\end{array}$ & $\begin{array}{c}0.31 \\
(2.03) \\
{[2.05]}\end{array}$ & $\begin{array}{c}0.17 \\
(1.60) \\
{[1.40]}\end{array}$ & $\begin{array}{c}1.34 \\
(3.26)\end{array}$ & $\begin{array}{c}0.33 \\
(1.54)\end{array}$ & $\begin{array}{c}0.12 \\
(0.77)\end{array}$ \\
\hline$\dot{P}$ (Inflation) & $\begin{array}{c}-0.53 \\
(-1.73) \\
{[-1.70]}\end{array}$ & $\begin{array}{c}0.17 \\
(0.80) \\
{[0.67]}\end{array}$ & $\begin{array}{c}-0.40 \\
(-2.47) \\
{[-2.19]}\end{array}$ & $\begin{array}{c}-0.61 \\
(-1.45)\end{array}$ & $\begin{array}{c}0.17 \\
(0.59)\end{array}$ & $\begin{array}{c}-0.45 \\
(-2.06)\end{array}$ \\
\hline$C$ (Candidate Evaluation) & $\begin{array}{c}7.29 \\
(3.82) \\
{[3.72]}\end{array}$ & $\begin{array}{c}1.68 \\
(1.60) \\
{[0.96]}\end{array}$ & $\begin{array}{c}1.33 \\
(1.38) \\
{[1.03]}\end{array}$ & $\begin{array}{c}7.40 \\
(3.01)\end{array}$ & $\begin{array}{c}1.81 \\
(0.93)\end{array}$ & $\begin{array}{c}1.39 \\
(1.00)\end{array}$ \\
\hline$D P E R$ (Incumbency: President) & $\begin{array}{c}1.93 \\
(1.02) \\
{[0.97]}\end{array}$ & - & - & $\begin{array}{l}1.66 \\
(0.70)\end{array}$ & - & - \\
\hline SINC (Incumbency: Senate) & - & $\begin{array}{l}16.62 \\
(8.97) \\
{[5.13]}\end{array}$ & - & - & $\begin{array}{l}15.02 \\
(2.57)\end{array}$ & - \\
\hline CINC (Incumbency: House) & 一 & - & $\begin{array}{c}30.30 \\
(11.92) \\
{[10.66]}\end{array}$ & - & - & $\begin{array}{l}34.98 \\
(6.58)\end{array}$ \\
\hline$M T$ (Mid-term) & - & $\begin{array}{c}-2.65 \\
(-2.22) \\
{[-1.95]}\end{array}$ & $\begin{array}{l}-2.83 \\
(-3.27) \\
{[-2.91]}\end{array}$ & - & $\begin{array}{l}-2.61 \\
(-1.84)\end{array}$ & $\begin{array}{l}-3.10 \\
(-2.85)\end{array}$ \\
\hline $\begin{array}{l}\text { Log-Likelihood } \\
R^{2}\end{array}$ & -64.81 & & & 0.82 & 0.49 & 0.73 \\
\hline
\end{tabular}

Note: Asymptotic $t$-statistics are in parentheses; bootstrapped $t$-statistics are in brackets.

\begin{tabular}{lcccccc}
\multicolumn{7}{c}{ Estimated Cross-Equation Error Covariances and Correlations } \\
& Estimated Error Covariances & \multicolumn{2}{c}{ Estimated Error Correlations } \\
& President & Senate & House & President & Senate & House \\
President & 4.17 & & & 1.00 & & \\
Senate & -0.83 & 6.48 & & -0.16 & 1.00 & \\
House & 0.05 & 4.03 & 3.54 & 0.01 & 0.84 & 1.00
\end{tabular}

Erikson, but it is larger than most previously reported estimates, and it is highly significant statistically. Inflation has an expected negative sign and is of marginal significance in the presidential equation.

Economic growth has smaller effects in the House and Senate equations. Given the national orientation of presidential elections (compared to House and Senate races), this should not be surprising. Nevertheless, the coefficients on economic 
TABLE 2

Tests of Cross-Equation Restrictions

\begin{tabular}{|c|c|c|c|c|}
\hline Null Hypothesis & Description & $\begin{array}{c}\text { Test } \\
\text { Statistic: } \\
\lambda_{w} \\
\end{array}$ & $\begin{array}{c}\text { Critical } \\
\text { Value: } \\
\chi_{.90}^{2} \\
\end{array}$ & Test Result \\
\hline 1. $\alpha_{1}=\beta_{1}=\gamma_{1}$ & Equality of all $\dot{Y}$ coefficients & 39.63 & 4.61 & Reject \\
\hline 2. $\alpha_{2}=\beta_{2}=\gamma_{2}$ & Equality of all $\dot{P}$ coefficients & 20.99 & 4.61 & Reject \\
\hline 3. $\alpha_{3}=\beta_{3}=\gamma_{3}$ & Equality of all $C$ coefficients & 9.17 & 4.61 & Reject \\
\hline 4. $\begin{aligned} \alpha_{1} / \alpha_{2} & =\beta_{1} / \beta_{2} \\
& =\gamma_{1} / \gamma_{2}\end{aligned}$ & $\begin{array}{l}\text { Equality of all rations of } \dot{Y} \text { and } \dot{P} \\
\text { coefficients }\end{array}$ & 2.47 & 4.61 & Fail to Reject \\
\hline 5. $\alpha_{1}=\beta_{1}$ & $\begin{array}{l}\text { Equality of } Y \text { coefficients, Presidential } \\
\text { and Senate equations }\end{array}$ & 16.61 & 2.71 & Reject \\
\hline 6. $\alpha_{1}=\gamma_{1}$ & $\begin{array}{l}\text { Equality of } Y \text { coefficients, Presidential } \\
\text { and House equations }\end{array}$ & 28.92 & 2.71 & Reject \\
\hline 7. $\beta_{1}=\gamma_{1}$ & $\begin{array}{l}\text { Equality of } \dot{Y} \text { coefficients, House and } \\
\text { Senate equations }\end{array}$ & 2.55 & 2.71 & Fail to Reject \\
\hline 8. $\alpha_{2}=\beta_{2}$ & $\begin{array}{l}\text { Equality of } \dot{P} \text { coefficients, Presidential } \\
\text { and Senate equations }\end{array}$ & 3.51 & 2.71 & Reject \\
\hline 9. $\alpha_{2}=\gamma_{2}$ & $\begin{array}{l}\text { Equality of } \dot{P} \text { coefficients, Presidential } \\
\text { and House equations }\end{array}$ & 0.17 & 2.71 & Fail to Reject \\
\hline 10. $\beta_{3}=\gamma_{3}$ & Equality of $P$ coefficients, House and Senate & 0.28 & 2.71 & Fail to Reject \\
\hline 11. $\beta_{5}=\gamma_{5}$ & $\begin{array}{l}\text { Equality of } M T \text { coefficients, House and } \\
\text { Senate equations }\end{array}$ & 0.11 & 2.71 & Fail to Reject \\
\hline 12. $\beta_{4}=\gamma_{4}$ & $\begin{array}{l}\text { Equality of } H I N C \text { and } S I N C \text { coefficients, } \\
\text { House and Senate equations }\end{array}$ & 25.78 & 2.71 & Reject \\
\hline 13. $\beta_{3}=\gamma_{3}$ & $\begin{array}{l}\text { Equality of } C \text { coefficients, House and } \\
\text { Senate equations }\end{array}$ & 0.28 & 2.71 & Fail to Reject \\
\hline 14. $\begin{aligned} \beta_{1} & =\gamma_{1}=\beta_{2} \\
& =\gamma_{2}=0\end{aligned}$ & $\begin{array}{l}P \text { and } Y \text { coefficients equal zero in both } \\
\text { House and Senate equations }\end{array}$ & 37.52 & 7.78 & Reject \\
\hline 15. $\begin{aligned} \beta_{1} & =\gamma_{1} \\
& =\gamma_{2}=0\end{aligned}$ & $\begin{array}{l}\dot{P} \text { and } \dot{Y} \text { coefficients equal zero in the } \\
\text { House equation and the } \dot{Y} \text { coefficient } \\
\text { equals zero in the Senate equation }\end{array}$ & 10.42 & 6.25 & Reject \\
\hline
\end{tabular}

Note: Wald tests of the indicated restrictions at the 0.10 significance level.

growth are properly signed and approach marginal significance levels under the $S U R$ estimation, even when we control for the effects of incumbency, coattails, and the mid-term dummy. Inflation is negatively signed and significant in the House equation, but not in the Senate equation. The strongest evidence that economic conditions matter for congressional elections is provided by a test of the hypothesis that all economic variable coefficients in the House and Senate equations jointly equal zero. That hypothesis is convincingly rejected (table 2 , test 14). A similar test (table 2, test 15 ) which excludes the anomalously signed inflation coefficient in the Senate equation supports an identical conclusion. We therefore find notably stronger evidence of conventional economic voting in congressional elections than Alesina-Rosenthal (1989) or Erikson (1990) did. 
Mid-term Effects and Incumbency Power. As Erikson (1989) did, we find that candidate evaluations have important impacts on presidential election outcomes. The presidential evaluations are also positively signed in the House and Senate equations, but the coefficients are small and fall short of significance at conventional levels. As a result, we conclude that coattails associated with the likability of the presidential candidate do not provide a good explanation for mid-term effects. Table 1 shows that correlations between the presidential vote function error and errors for the House and Senate equations are small, so the "reversion to the mean" hypothesis also fails to explain mid-term effects. These results for the Congress are in accord with those of Erikson (1988).

The mid-term dummy is highly significant in both House and Senate equations and it accounts for almost a three percentage point drop in the share of the incumbent president's party in each equation. These results are consistent with both the Alesina-Rosenthal (1989) argument for "moderating elections" and the Erikson (1988) finding that mid-term effects reflect a penalty for the party in power.

Incumbency effects measured by $D P E R$ are not significant in the presidential vote function, but $H I N C$ and $S I N C$ have large significant effects in the House and Senate equations. Estimated incumbency effects are larger in the House than in the Senate. This result is consistent with cross-sectional evidence showing greatest advantages to incumbency in House races.

SUR Estimation and Tests of Cross-Equation Restrictions. Table 1 reports a large positive correlation between the House and Senate equation errors; this suggests that notable efficiency gains from the use of the $S U R$ technique are likely. Relatedly, we find that coefficient standard errors for the $S U R$ estimates are, with few exceptions, smaller than those for their OLS counterparts. This is true of both asymptotic and bootstrapped standard errors. As a result, significance levels are higher under $S U R$ even though the estimates themselves are similar across the $O L S$ and $S U R$ estimations.

Table 2 provides results of tests of hypotheses involving cross-equation comparisons. ${ }^{12}$ We noted earlier that effects of economic growth and presidential candidate evaluations are largest in the presidential voting equation; the Wald test reported in table 2 reveals that the relevant coefficients in the presidential vote equation are significantly larger than those in the congressional equations. We also noted that Senate and House equations are similar with regard to the effects of economic growth, candidate evaluations, and mid-term effects-table 2 shows that we cannot reject restrictions implying equal coefficients for these variables across House and Senate equations. Despite apparent differences in inflation coefficients, we are also unable to reject the hypothesis of equal relative importance of

\footnotetext{
${ }^{12}$ Given the similarity of the asymptotic and bootstrapped variance-covariance matrices, we have chosen to report only the asymptotic test statistics, which are most easily computed using the TSP statistical package.
} 
growth and inflation effects across equations. ${ }^{13}$ Thus, while overall economic performance matters most in presidential elections, the standard by which performance is judged is consistent across the three election types. Finally, we noted earlier that both House and Senate equations have significant incumbency effects; table 2 reveals that these effects are significantly larger in the House equation.

\section{CONCLUSIONS}

We have jointly estimated vote functions for the presidency, the House, and the Senate using a seemingly unrelated regressions technique that permits unequal numbers of observations across equations. Our method offers efficiency gains relative to ordinary least squares and it also facilitates tests involving cross-equation comparisons.

Our results confirm previous studies in showing that economic growth has large effects on vote shares in presidential elections. Economic conditions are less important for House and Senate election outcomes, but with the $S U R$ estimator we detect significant impacts even when mid-term effects, coattails, and incumbency power are controlled for. Our results cannot reject the view that the relative importance of income growth and inflation is unchanged across election types. We find that Senate and House vote functions are generally quite similar, but that incumbency power is more important in House elections. As in Erikson (1988) and Alesina-Rosenthal (1989), mid-term effects in House and Senate elections appear to reflect a "presidential penalty."

Manuscript submitted 6 fuly 1990

Final manuscript received 31 January 1992

\section{REFERENCES}

Alesina, Alberto, and Howard Rosenthal. 1989. "Partisan Cycles in Congressional Elections and the Macroeconomy." American Political Science Reviem 83:373-98.

Arcelus, Francisco, and Allan H. Meltzer. 1975. "The Effect of Aggregate Economic Variables on Congressional Elections." American Political Science Review 69:1232-39.

Calvert, Randall L., and John A. Ferejohn. 1984. "Presidential Coattails in Historical Perspective." American Fournal of Political Science 28:127-46.

Chappell, Henry W., Jr. 1990. "Economic Performance, Voting, and Political Support: A Unified Approach." Review of Economics and Statistics 72:313-20.

Efron, Bradley. 1982. The Jackknife, the Bootstrap and Other Resampling Plans. Philadelphia: Society for Industrial and Applied Mathematics.

Erikson, Robert S. 1988. "The Puzzle of the Midterm Loss." The fournal of Politics 50:1011-29.

Erikson, Robert S. 1989. "Economic Conditions and the Presidential Vote." American Political Science Review 83:567-73.

${ }^{13}$ Formally, we fail to reject the hypothesis that $\alpha_{1} / \alpha_{2}=\beta_{1} / \beta_{2}=\gamma_{1} / \gamma_{2}$. When this restriction is imposed in estimation, inflation is negatively signed but insignificant in the model, but other results are similar to those reported here. 
Erikson, Robert S. 1990. "Economic Conditions and the Congressional Vote: A Review of the Macrolevel Evidence." American fournal of Political Science 34:373-99.

Fair, Ray C. 1988. "The Effect of Economic Events on Votes for President: A 1984 Update." Political Behavior 10:168-79.

Hocking, R. R., and W. B. Smith. 1968. "Estimation of Parameters in the Multivariate Normal Distribution with Missing Observations." Fournal of the American Statistical Association 63:154-73.

Kramer, Gerald. 1971. "Short Term Fluctuations in U.S. Voting Behavior, 1896-1964." American Political Science Reviem 65:131-43.

Lepper, Susan J. 1974. "Voting Behavior and Aggregate Policy Targets." Public Choice 18:67-82.

Schmidt, Peter. 1977. "Estimation of Seemingly Unrelated Regressions with Unequal Numbers of Observations." Fournal of Econometrics 5:365-77.

Stigler, George J. 1973. "General Economic Conditions and National Elections." American Economic Review 63:160-67.

Tufte, Edward R. 1975. "Determinants of the Outcomes of Mid-term Congressional Elections." American Political Science Review 69:812-26.

Tufte, Edward R. 1978. Political Control of the Economy. Princeton: Princeton University Press.

White, Halbert. 1982. "Maximum Likelihood Estimation of Misspecified Models." Econometrica 50:1-25.

Zellner, Arnold, 1962. "An Efficient Method of Estimating Seemingly Unrelated Regressions and Tests for Aggregation Bias." Journal of the American Statistical Association 57:348-68.

Henry W. Chappell, Jr. is professor of economics, University of South Carolina, Columbia, SC 29208.

Motoshi Suzuki is assistant professor of political science, University of North Texas, Denton, TX 76203. 
Copyright of Journal of Politics is the property of Cambridge University Press and its content may not be copied or emailed to multiple sites or posted to a listserv without the copyright holder's express written permission. However, users may print, download, or email articles for individual use. 